\title{
CPU86017-RS attenuate hypoxia-induced testicular dysfunction in mice by normalizing androgen biosynthesis genes and pro-inflammatory cytokines
}

\author{
Guo-lin ZHANG\#, Feng YU*, De-zai DAI*, Yu-si CHENG, Can ZHANG, Yin DAI \\ Faculty of Pharmacy, China Pharmaceutical University, Nanjing 210009, China
}

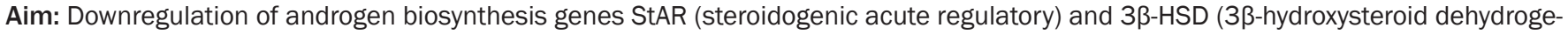
nase) contributes to low testosterone levels in hypoxic mice and is possibly related to increased expression of pro-inflammatory cytokines in the testis. The aim of this study is to investigate the effects of CPU86017-RS that block $\mathrm{Ca}^{2+}$ influx on hypoxia-induced testis insult in mice.

Methods: Male ICR mice were divided into 5 groups: control group, hypoxia group, hypoxia group treated with nifedipine (10 mg/kg), hypoxia groups treated with CPU86017-RS (60 or $80 \mathrm{mg} / \mathrm{kg}$ ). Hypoxia was induced by placing the mice in a chamber under $10 \% \pm 0.5 \%$ 02 for $28 \mathrm{~d}$ ( $8 \mathrm{~h}$ per day). The mice were orally administered with drug in the last $14 \mathrm{~d}$. At the end of experiment the testes of the mice were harvested. The mRNA and protein levels of StAR, 3ß-HSD, connexin 43 (Cx43), matrix metalloprotease 9 (MMP9), endothelin receptor $A\left(E T_{A} R\right)$ and leptin receptor $(\mathrm{OBRb})$ were analyzed using $\mathrm{RT}-\mathrm{PCR}$ and Western blotting, respectively. The malondialdehyde $(\mathrm{MDA})$, lactate dehydrogenase (LDH), succinate dehydrogenase $(\mathrm{SDH})$ and acid phosphatase (ACP) levels were measured using biochemical kits. Serum testosterone concentration was measured with radioimmunoassay.

Results: Hypoxia significantly increased the MDA level, and decreased the LDH, ACP and SDH activities in testes. Meanwhile, hypoxia induced significant downregulation of StAR and 3ß-HSD in testes responsible for reduced testosterone biosynthesis. It decreased the expression of $\mathrm{Cx} 43$, and increased the expression of MMP9, ETAR and OBRb, leading to abnormal testis function and structure. These changes were effectively diminished by CPU86017-RS ( $80 \mathrm{mg} / \mathrm{kg}$ ) or nifedipine (10 mg/kg).

Conclusion: Low plasma testosterone level caused by hypoxia was due to downregulation of StAR and $3 \beta-H S D$ genes, in association with an increased expression of pro-inflammatory cytokines. These changes can be alleviated by CPU86017-RS or nifedipine.
\end{abstract}

Keywords: intermittent hypoxia; testicular injury; CPU86017-RS; nifedipine; StAR; 3ß-hydroxysteroid dehydrogenase; matrix metalloprotease 9; endothelin receptor A; connexin 43; OBRb

Acta Pharmacologica Sinica (2012) 33: 470-478; doi: 10.1038/aps.2011.175; published online 19 Mar 2012

\section{Introduction}

Oxygen is essential and critical for life in humans and other mammals ${ }^{[1,2]}$. When subjected to a low supply of oxygen, a series of pathological changes are initiated in cells and tissues, leading to ischemia, stroke, hemorrhage and many other cardiopulmonary diseases ${ }^{[3,4]}$. Certain genes whose transcription is activated by exposure of the cell to hypoxia accelerate the appearance of pro-inflammatory cytokines such as ROS (reactive oxygen species), and induce the activation of the endothelin system ${ }^{[5,6]}$. Hypoxia, which is a ubiquitous pathological process, has serious adverse effects on the respiratory and

\footnotetext{
"The two authors contributed equally to this paper.

* To whom correspondence should be addressed.

E-mail dezaidai@vip.sina.com

Received 2011-08-22 Accepted 2011-11-18
}

cardiovascular systems $^{[7]}$, and possibly damages the reproductive system as well. A decline in the ability of conceive has frequently been noticed in population lived in highland area.

Male hypogonadism causes degenerative changes in the testes and is characterized by low-concentrations of serum testosterone associated with testicular lesions ${ }^{[8]}$. An over-activated ET-ROS (endothelin-reactive oxygen species) system enhances activities of some cellular inflammatory factors responsible for the genesis of male hypogonadism. Emerging data suggest that the ET system mediates pathological changes leading to male hypogonadism ${ }^{[9]}$ and testopathy in individuals with diabetic mellitus ${ }^{[10-12]}$. Matrix metalloprotease (MMPs) are the most important proteases participating in extracellular matrix degradation and remodeling and MMP9 takes an important part in the maintenance of the normal structure and function of the seminiferous tubules. Intercellular gap junction com- 
munication is operated by a family of proteins known as connexins, among them connexin 43 (Cx43) is the most abundant and extensively distributed of the connexins and it is known to be affected in disease ${ }^{[13,14]}$. An alteration of Cx43 is concerned in abnormal function and structure of the testis ${ }^{[15]}$. Testicular disorders resulting from intermittent hypoxia exposure may be caused by a deficiency in Cx43-mediated gap junctional signaling in the testis.

CPU86017 is synthesized by China Pharmaceutical University through modification of the berberine moiety. In pulmonary hypertension induced by hypoxia, or by the inflammatory reagent monocrotaline, CPU86017 suppresses the activation of the endothelin system and the formation of oxygen free radicals ${ }^{[7,16]}$. CPU86017 also blocks L-type calcium channels ${ }^{[17]}$. This calcium- antagonism activity is thought to underlie its effect of relieving cardiovascular disorder ${ }^{[18]}$. CPU86017 and its isomer CPU86017-RS were found to act as a protection against tissue damage from various pathological factors. They confer this protection by blocking the ET-ROS pathway and subsequently attenuating the pro-inflammatory cytokines involved in the pathologies caused by hypoxia-induced pulmonary hypertension and cardiovascular abnormalities ${ }^{[7,16-21]}$. Hypoxia-induced pulmonary hypertension causes ROS production $^{[22]}$, and nifedipine has been recommended as an effective therapy for managing hypoxic pulmonary hypertension in clinical settings ${ }^{[23-25]}$.

We hypothesized that the male hypogonadism caused by intermittent hypoxia is a result of a chronic inflammatory response in which over-activated cytokines such as ET, leptin, and MMPs, in addition to the downregulation of Cx43, contribute to the pathology in hypoxic testes. We further hypothesized that these changes could be initiated by an increase in calcium influx. In this study, we aimed to determine whether the hypoxia-induced upregulation of inflammatory cytokines and downregulation of testosterone biosynthesis genes in the testis, which are attributed to an enhanced influx of calcium, could respond to nifedipine or CPU 86017-RS.

\section{Materials and methods}

\section{Animals and treatment}

Male ICR mice, weighing 22-25 g, were bought from the Zhejiang Experimental Animal Center [License Number: SCXK(Z)20080033]. All procedures performed on the animals were conducted in accordance with the Animal Regulations of Jiangsu Province, China.

Mice were randomly divided into 5 groups $(n=6)$. The groups were as follows: a control group, a hypoxia group, a hypoxia group also treated with nifedipine $(10 \mathrm{mg} / \mathrm{kg}$ po, Changzhou Kangpu Pharmaceutical Co, Ltd, China, batch number: 0910004), and two groups treated with CPU86017-RS (RS60, $60 \mathrm{mg} / \mathrm{kg}$; RS80, $80 \mathrm{mg} / \mathrm{kg}$ po, supplied by the Department of Medicinal Chemistry of China Pharmaceutical University, batch number: 20090301). Chronic exposure to intermittent hypoxia was performed as previously described ${ }^{[6,7]}$. Briefly, for $8 \mathrm{~h}$ per day for $28 \mathrm{~d}$, the mice were placed in a normobaric hypoxic chamber in which the oxygen content was maintained at $10 \% \pm 0.5 \%$. The interventions by nifedipine or CPU86017-RS were applied during the last 2 weeks of hypoxia exposure.

\section{Biochemical assays}

The testis was harvested from mice after cervical dislocation and $100 \mathrm{mg}$ of testicular tissue was homogenized in 10 volume of physiological saline. MDA, LDH, SDH, and ACP levels were measured by using biochemical kits (Nanjing Jiancheng Institute of Bio-engineering Company, Nanjing, China). Serum testosterone concentrations were measured by radioimmunoassay (RIA) with kits purchased from the institute of Jiuding Medical Bio-engineering company (Tianjin, China). These measurements were made in accordance with previous reports $^{[9-11]}$.

\section{RT-PCR}

The testes were harvested and total RNA was extracted using the Trizol solution. cDNA was synthesized as described previously (Invitrogen, Carlsbad, CA, USA) ${ }^{[14]}$. The primer (Invitrogen Trading Co, Ltd, Shanghai, China) sequences were used

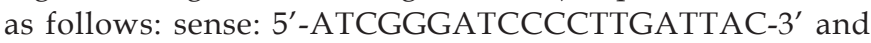
antisense: 5' -ACAGCAACAGAGGCAGGACT-3' for $\mathrm{ET}_{\mathrm{A}} \mathrm{R}$, sense: 5'-CGACATAGACGGCATCCAG-3' and antisense: 5'-CTGTCGGCTGTGGTTCAGT-3' for MMP9, sense: 5'-TACCACGCCACCGGCCCA-3' and antisense: 5'-GCATTTTGGCTGTCGTCAGG-3' for Cx43, sense: 5' -AGAATTGTTCCTGGGCACAAG-3' and antisense: 5'-ACACTCATCCTCACAGGTTCC-3' for OBRb, sense: 5'-AACTTTGGCATTGTGGAAGG-3' and antisense: 5'-GGAGACAACCTGGTCCTCAG-3' for GAPDH.

\section{Western blotting}

After the mice were sacrificed, proteins of testes were extracted (Biouniquer Biotechnology Co, Ltd, Hangzhou, China) and Western blotting was conducted as described previously ${ }^{[6]}$. The sources of antibodies were listed as below: polyclonal rabbit anti-ET $\mathrm{A}_{\mathrm{A}} \mathrm{R}-\mathrm{IgG}$, polyclonal rabbit anti-StAR-IgG and polyclonal rabbit anti-MMP9-IgG were purchased from Santa Cruz Biotechnology Inc, USA; polyclonal rabbit anti-Cx43IgG, polyclonal rabbit anti- $\beta$-actin-IgG, polyclonal rabbit antiOBRb-IgG and horseradish peroxidase (HRP)-conjugated goat secondary antibody IgG were purchased from Wuhan Boster Biological Technology, Wuhan, China.

\section{Assessment of testis pathology}

The testis tissues, fixed with neutral $10 \%$ formalin, were embedded in paraffin and sliced into $4-\mu \mathrm{m}$-thick sections and stained with hematoxylin-eosin (HE). All pictures were viewed under an inverted microscope (Nikon TE 2000-U, Japan) by a pathologist blinded to the experiment.

\section{Immunohistochemical fluorescence assay}

The immunohistochemical fluorescence assay were conducted as previously described ${ }^{[26]}$. Paraffin-embedded testicular tissue was sliced into $4-\mu \mathrm{m}$-thick sections, dewaxed with xylene 
2 times and dehydrated with decreasing concentrations of ethanol $(100 \%, 95 \%, 90 \%, 80 \%$, and $70 \%)$. The sections were then placed in a 3:4 ratio solution of sodium-citrate:citrate, microwaved on full power for 8 min and soaked in a $3 \% \mathrm{H}_{2} \mathrm{O}_{2^{-}}$ methanol solution for $15 \mathrm{~min}$ to inactivate enzymes. The slices were then incubated in primary antibody $(1: 100$, polyclonal rabbit anti-3 $\beta$-hydroxysteroid dehydrogenase (3 $\beta$-HSD)-IgG, Novus Biological LLC, USA) for 2 h, washed 3 times with PBS, incubated with FITC-labeled secondary antibodi+es (1:400, KeyGEN BioTECH, Nanjing, China) for $1 \mathrm{~h}$ at $37^{\circ} \mathrm{C}$, washed 3 times and stained with DAPI (KeyGEN BioTECH, Nanjing, China) for $10 \mathrm{~min}$ at room temperature in the dark. All slides were viewed with a fluorescence microscope (OLYMPUS IX51, Japan).

\section{Statistical analysis}

All data were analyzed using SPSS11.5 (USA) software and are presented as the mean \pm SD. Statistics were evaluated using one-way analysis of variance followed by a Dunnett's test. The Student Newman-Keuls test was performed when the variances were equal, and the Games-Howell test was used when the variances were not equal. A probability value of $P<0.05$ was considered statistically significant.

\section{Results}

Testicular MDA, ACP, SDH, and LDH

Oxidative stress occurs in testicular tissues following exposure to intermittent hypoxia. In the testis, the production of MDA, an indication of oxidized lipid substances from an excess of reactive oxygen species (ROS), was increased by $177.1 \%$ $(P<0.01)$ compared to controls. By contrast, the activities of $\mathrm{ACP}, \mathrm{SDH}$, and $\mathrm{LDH}$, which are the main energy suppliers for both testosterone biosynthesis and cell maturation during spermatogenesis, were decreased in hypoxic testes by $42.1 \%$ $(P<0.01), 34.3 \%(P<0.01)$ and $57.1 \%(P<0.01)$, respectively, compared to controls. A reduction in these enzymatic activities was, at least in part, related to the testicular lesions induced by the 28-d exposure to intermittent hypoxia, which led to low testosterone production in these mice. These abnormalities were decreased by interventions with either CPU86017-RS or nifedipine (Figure 1).

\section{Serum testosterone and StAR}

Low serum testosterone has been recognized as the main criterion for clinical diagnosis of male hypogonadism. Therefore, we measured serum testosterone levels. In this study, serum testosterone levels, which are very sensitive to hypoxia, decreased by $85.0 \%(P<0.01)$ in the hypoxic testis compared to the control group (Figure 2A). The biosynthesis of testosterone depends on a series of gene activities that convert cholesterol to testosterone. The first step in this series of reactions involves the StAR-controlled uptake of cholesterol into the mitochondria. The expression of the testosterone biosynthesis gene StAR was downregulated by $32 \%(P<0.01)$ at the mRNA level and $36.4 \%(P<0.01)$ at the protein level relative to controls (Figures 2B, 2C).
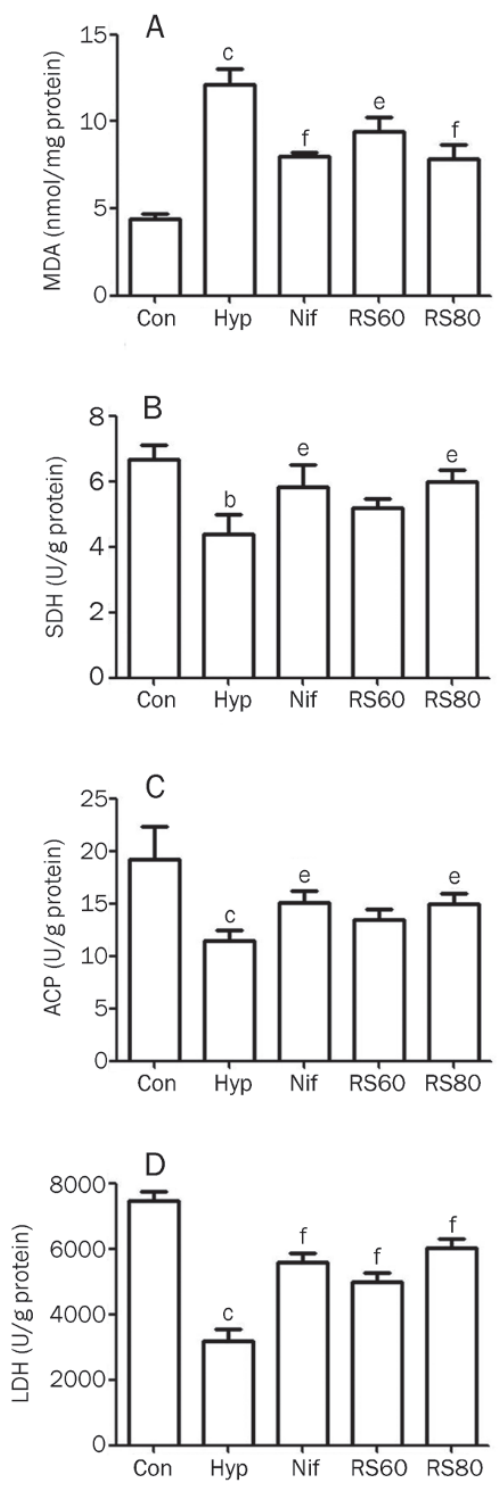

Figure 1. Testicular MDA increased significantly in hypoxic mice, accompanied with a reduction of SDH, ACP, and LDH dramatically, indicating that both oxidative stress and short of energy supply in the hypoxic testis were significant. These changes were obviously alleviated by the medication of CPU86017-RS and nifedipine. $n=6$. Mean \pm SD. ${ }^{b} P<0.05,{ }^{c} P<0.01$ vs control. ${ }^{\mathrm{e}} P<0.05,{ }^{\mathrm{f}} P<0.01$ vs hypoxia.

\section{Pathological changes}

The morphological arrangement of the seminiferous tubules was precisely layered and contained the spermatogenetic and Sertoli's cells associated with an intact basement. As in normal physiological conditions, these tubules were filled with spermatozoa that were concentrated at the center of the lumen and were surrounded by a clearly structured reproductive epithelium. The inter-tubule space contained an abundance of Leydig's cells, which are responsible for the active production of androgen. In contrast, the seminiferous tubules in the hypoxic group were badly damaged; their multi-layer reproductive endothelium was destroyed; they had greatly 
A

Testosterone

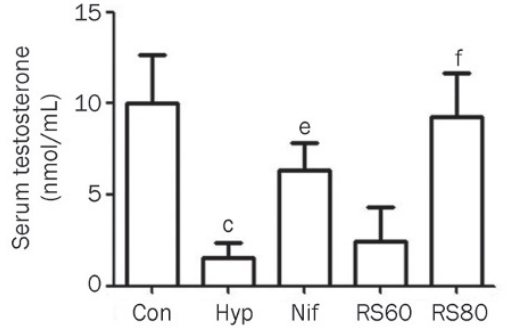

B

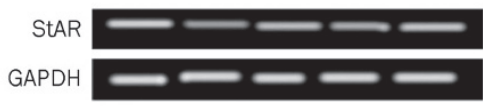

C

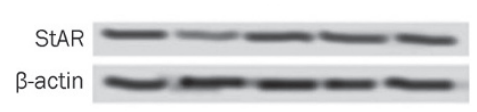

Figure 2. Serum testosterone content and expressions of StAR were decreased distinctly in mice suffering from hypoxia, which were neutralized by medication of CPU86017-RS. $n=6$. Mean \pm SD. ${ }^{\mathrm{c}} P<0.01$ vs control. ${ }^{\mathrm{e}} P<0.05,{ }^{\mathrm{f}} P<0.01$ vs hypoxia.

decreased amounts of spermatozoa in the lumen; and they had distorted reproductive epithelial and Sertoli's cells. The hypoxic mice also had a decreased number of Leydig's cells in the intra-tubular space. CPU86017-RS and nifedipine treatment preserved the normal appearance of the seminiferous tubules and the number of Leydig's cells in the inter-tubular space (Figure 3A-3E).

\section{Immunofluorescence imaging and Western blotting of 3 3 -HSD}

To collect further evidence of the existence of hypoxic lesions in the testis, $3 \beta-H S D$, a specific biomarker of Leydig's cell in the testis, was targeted. $3 \beta$-HSD is involved in many of the steps in the synthesis of testosterone from cholesterol that occur in the mitochondria of Leydig's cells and is therefore critical for androgen biogenesis. The location and abundance of $3 \beta$-HSD conjugated to Leydig's cells in the space within the tubules were clearly observed with the green signal from the immunofluorescence assay, and functioning Leydig's cells were clearly observed in the control mice (Figure 3F). The green fluorescence intensity of Leydig's cells was greatly reduced following exposure to intermittent hypoxia, in agreement with the changes in histology and biomarkers and the reduced serum testosterone concentration. The recovery of the Leydig's cells labeled with immunofluorescence was significant in mice treated with either nifedipine or CPU86017RS (Figure 3G-3K). In parallel experiments, Western blots revealed a significant decrease in the protein expression of $3 \beta$-HSD $(P<0.01)$ compared to controls. CPU86017-RS and nifedipine treatment increased the mRNA and protein expression of $3 \beta-H S D$ (Figure 3L, 3M).

\section{$\mathrm{ET}_{\mathrm{A}} \mathrm{R}$ and $\mathrm{OBRb}$ expression}

Leptin and its receptors greatly affect the male reproductive epithelium during developmental and postnatal periods. In the present study, we found elevated levels of OBRb mRNA and protein expression in the testis (Figure 4A, 4B), as well as an upregulation of $\mathrm{mRNA}$ and protein levels of $\mathrm{ET}_{\mathrm{A}} \mathrm{R}$ (Figure $4 \mathrm{C}, 4 \mathrm{D})$. Activated $\mathrm{ET}_{\mathrm{A}} \mathrm{R}$ is always accompanied by an increase in oxidants. Therefore, the upregulation of $\mathrm{ET}_{\mathrm{A}} \mathrm{R}$ is indicative of a state of oxidative stress in the hypoxic testes. CPU86017-RS and nifedipine neutralized the abnormal expression of $\mathrm{OBRb}(P<0.01)$ and $\mathrm{ET}_{\mathrm{A}} \mathrm{R}(P<0.01)$ compared with hypoxic mice that did not receive treatment (Figure 4$)$.

\section{Cx43 and MMP9}

Hypoxia-induced male hypogonadism may be the consequence of impairment of the extracellular matrix. This is relevant because the extracellular matrix is important in gap junctional communication through the intercellular space of cells in the testes. Cx43 mRNA and protein expression decreased by $43.6 \%$ and $42.7 \%(P<0.01)$, respectively, in the hypoxia group compared to controls (Figure $5 \mathrm{~A}, 5 \mathrm{~B}$ ), indicating that the intercellular gap junctional communications in the testis were insufficient. This finding coincided with the depressed testicular function observed after episodes of hypoxia. This Cx43 impairment contributed to the decreased testosterone production in the testes. In contrast, MMP9 mRNA and protein expression was increased by $70.8 \%$ and $93.8 \%(P<0.01)$, respectively (Figure 5C,5D), providing evidence for the idea that intermittent hypoxia induces remodeling of the extracellular matrix. Extracellular matrix remodeling was significant and resulted in an alteration in the intercellular space that affected signal transduction through intercellular gap junctions. CPU86017-RS and nifedipine relieved the hypoxia-induced insults to the reproductive system, partly by normalizing the extracellular matrix and gap junctional communication in the testes.

\section{Discussion}

Normobaric hypoxia is a common pathological process that damages multiple metabolic and cardiovascular systems ${ }^{[27]}$. Hypoxia inhibits spermatogenesis by damaging the seminiferous epithelium and promoting the apoptosis of spermatogenic cells in the reproductive system.

Serum testosterone concentrations less than $300 \mathrm{ng} / \mathrm{dL}$ serve as a criterion for the diagnosis of male hypogonadism ${ }^{[28]}$. 

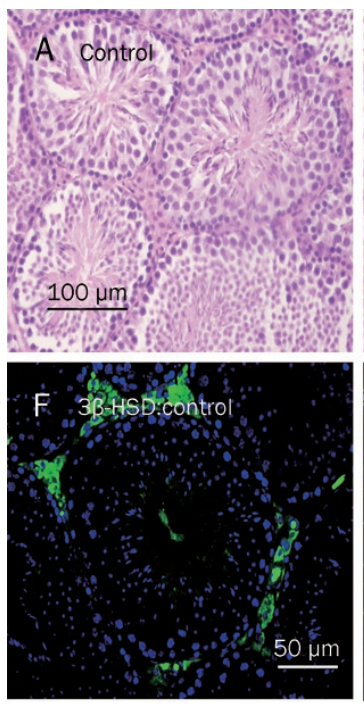

K 3ß-HSD positive cell ratio

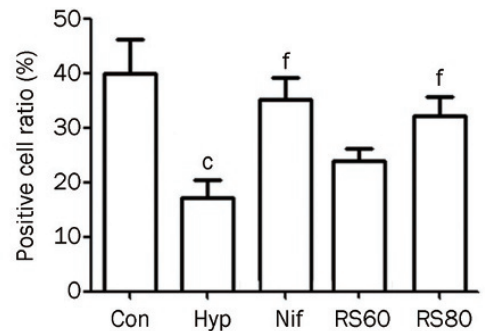

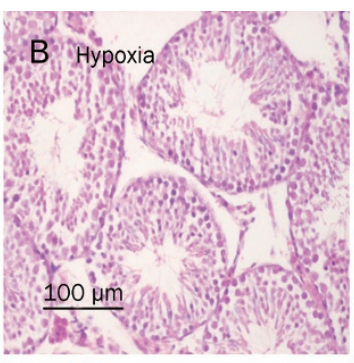
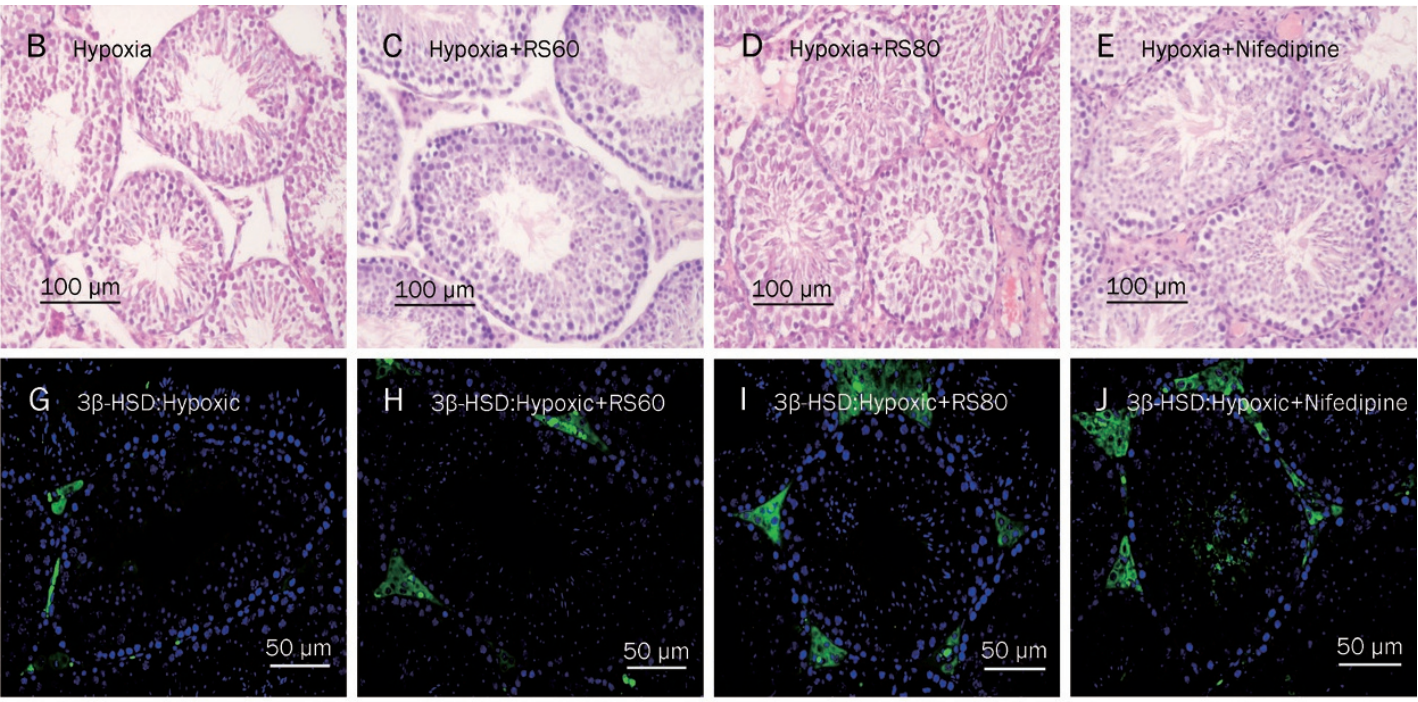

M
$\mathrm{L}$

mRNA levels of 3ß-HSD

3ß-HSD

$\beta$-actin

Protein levels of $3 \beta-H S D$ 3ß-HSD GAPDH
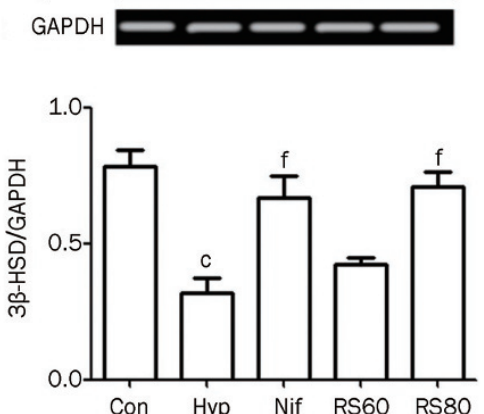

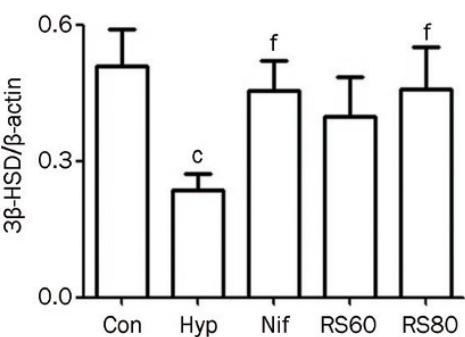

Figure 3. Histological changes of the testes and abnormal expression of 3ß-HSD (green fluorescence) were observed. A-E: Histological changes in the testis were found in H+E stained slices. (A) Control; (B) Hypoxia; (C) Hypoxia+RS60; (D) Hypoxia+RS80; (E) Hypoxia+nifedipine. The cellular distribution and expression of $3 \beta-H S D$ were detected by immunofluorescence assay in green color (F-J), and RT-PCR and western blotting were also employed. (F) 3ß-HSD in normal control; $(\mathrm{G})$ in hypoxic mice; $(\mathrm{H})$ Hypoxia+RS60; (I) Hypoxia+RS80; (J) Hypoxia+nifedipine; (K) positive cell ratio of 3ß-HSD; (L and M) mRNA and protein levels of 3ß-HSD.

Testosterone serum concentrations decreased significantly after exposure to intermittent hypoxia, and this decrease was due to decreased expression of the androgen biosynthesis genes, StAR and 3 $\beta$-HSD. Decreased testosterone production induced by intermittent hypoxia may result from inhibition of cholesterol desmolase activity (cleavage of cholesterol side-chains by cytochrome P450 and P450scc) and the cAMP pathway; therefore, decreased testosterone production may be related to abnormal intracellular calcium levels ${ }^{[29,30]}$. Testosterone replacement therapy, which is widely used to treat male hypogonadism in clinical settings, elevates serum testosterone levels directly and improves erectile dysfunction. However, although this therapeutic approach suppresses the hypothalamus-pituitary-testis feed back loop, it does not alleviate testicular lesions ${ }^{[10,11]}$. Increasing the gene expression of both StAR and $3 \beta-H S D$ represents a basic approach to normalize the hypoxia-induced decrease in testicular function. In the present study, the hypoxia-induced downregulation of these two genes was significantly attenuated by the calcium antago- nists nifedipine and CPU86017-RS.

In the testes, the activity of $\mathrm{ACP}, \mathrm{LDH}$, and $\mathrm{SDH}$ is a crucial source of energy for both testosterone biosynthesis and spermatogenic epithelium maturation. Therefore, the activities of $\mathrm{ACP}, \mathrm{LDH}$, and $\mathrm{SDH}$ can be used as markers for predicting testis function. ACP is essential for protein synthesis and is actively involved in germ development and Sertoli's cell function. $\mathrm{LDH}$ and $\mathrm{SDH}$ are present during spermatogenesis and are found in Sertoli's cells, where they take an active part in supplying energy by metabolizing glucose ${ }^{[28]}$. They also play an important role in the transformation of testosterone from cholesterol in Leydig's cells.

Calcium channels in the cell membrane actively control the influx of $\mathrm{Ca}^{2+}$, which influences the intracellular levels of free $\mathrm{Ca}^{2+}$. Consequently, the intracellular levels of free $\mathrm{Ca}^{2+}$ markedly affect the genesis and maturation of sperm cells ${ }^{[31,32]}$. Sperm and Leydig's cells containing L-type voltage-dependent calcium channels are crucial for sperm-egg fusion and testosterone biosynthesis. In this study, nifedipine served as the 

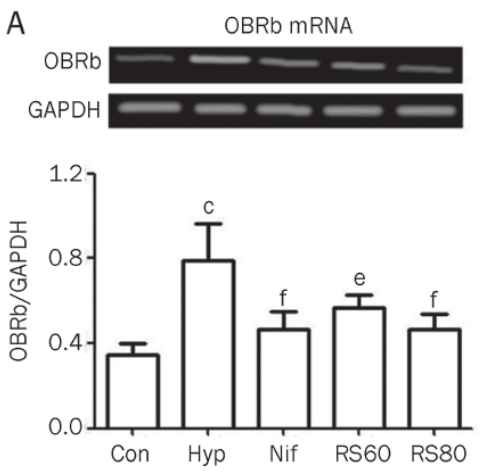

B
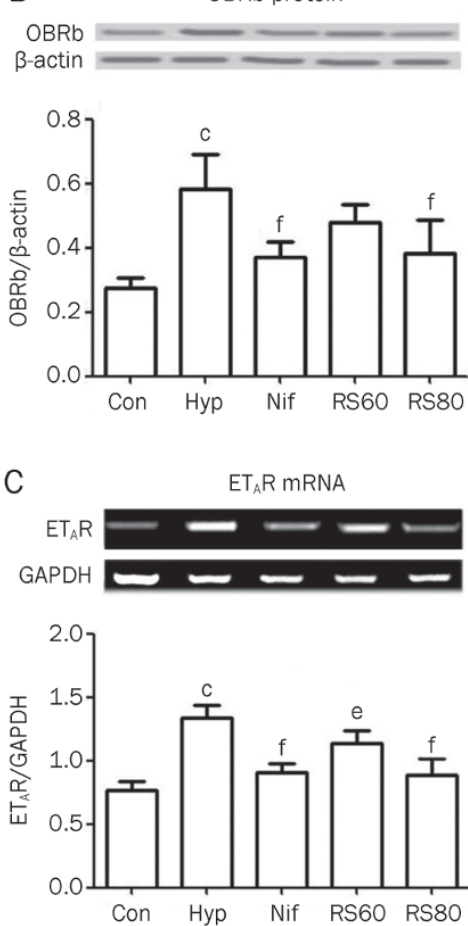

D
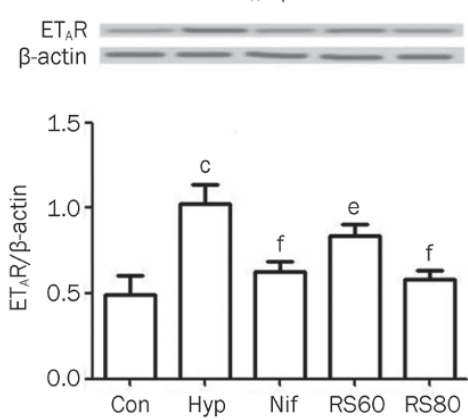

Figure 4. An increase in expression of $E T_{A} R$ and $O B R b$ was found in hypoxic mice, which was blunted by CPU86017-RS compound and nifedipine respectively. $n=6$. Mean \pm SD. ${ }^{c} P<0.01$ vs dontrol. ${ }^{e} P<0.05$, ${ }^{\mathrm{f}} P<0.01$ vs hypoxia.

positive control that limited the calcium influx and reversed the increase in calcium influx observed following exposure to
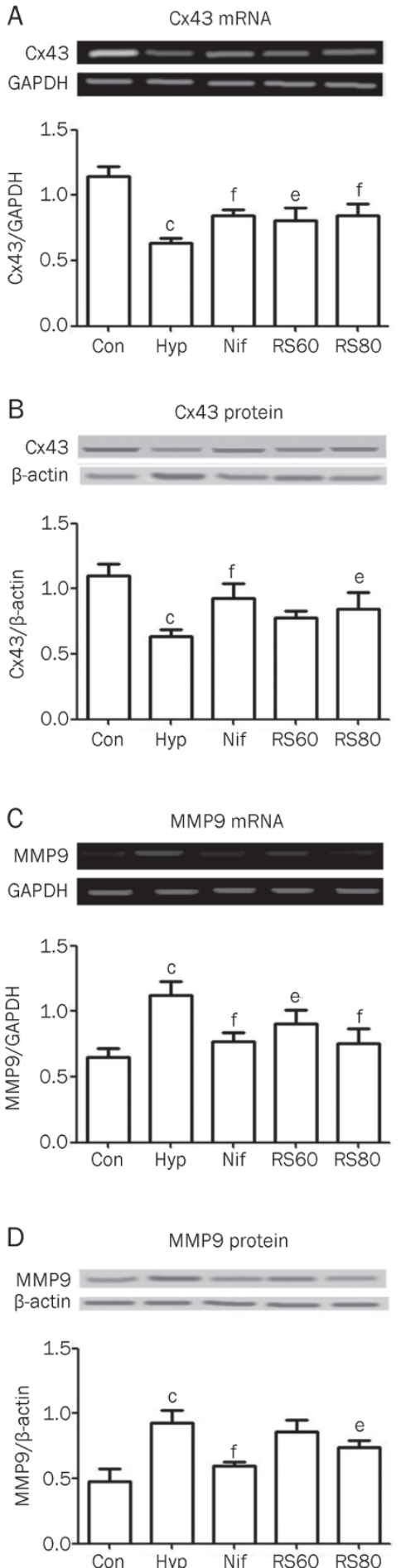

Figure 5. Abnormal expressions of MMP9 and Cx43 were found in the testis after hypoxia exposure and were reversed by CPU86017-RS and nifedipine dramatically. $n=6$. Mean \pm SD. ${ }^{\mathrm{c}} P<0.01$ vs control. ${ }^{\mathrm{e}} P<0.05$, ${ }^{\mathrm{f}} P<0.01$ vs hypoxia.

low levels of oxygen. Under physiological conditions, calcium concentrations in the extracellular space are about a million times higher than those in the cytosol. Voltage-dependent L-type channels are important in living cells, and upon activa- 
tion under physiological conditions, a small amount of $\mathrm{Ca}^{2+}$ moves through these channels and promotes a series of $\mathrm{Ca}^{2+}$ activated events necessary for normal testicular function. An overload of $\mathrm{Ca}^{2+}$ influx caused by hypoxia contributes significantly to hypoxia-induced testicular damage. Blocking this calcium influx with nifedipine reverses the hypoxia-induced increase in overloaded free $\mathrm{Ca}^{2+}$ levels in the testicular cells, thereby decreasing the pathological changes secondary to hypoxia. In addition, CPU86017 has been found to act as a calcium antagonist in the cardiovascular system ${ }^{[17,18]}$, and this calcium antagonism may underlie the mechanism by which this compound acts to relieve hypoxia-induced testicular abnormalities. The disturbance of calcium homeostasis in reproductive cells is the main cause of the low testosterone concentrations and abnormal pro-inflammatory biomarkers observed in hypoxic testes. These changes were relieved by the CPU86017-RS isomer, and the relief was comparable to that observed with nifedipine. We also emphasize that under physiological conditions calcium influx is necessary for the maintenance of normal testicular size and function. Large doses of nifedipine caused a decrease in testosterone biosynthesis and a reduction in testicular size in prepubertal mice ${ }^{[33]}$.

An over-activated endothelin system has been found to be involved in several pathologies in the cardiovascular system and to participate in myocardium fibrosis through the activation of MMP2/9 in heart fibroblasts ${ }^{[14]}$. Our previous studies have suggested that an upregulation of $\mathrm{ET}_{\mathrm{A}} \mathrm{R}$ is closely linked to an increase in ROS production, which forms a so-called ETROS pathway in diabetic cardiomyopathy, vascular disorder and nephropathy ${ }^{[3,35]}$. ROS are over-produced in hypoxia and facilitates the activation of $\mathrm{ET}_{\mathrm{A}} \mathrm{R} . \mathrm{ET}_{\mathrm{A}} \mathrm{R}$ then provides positive feedback to stimulate the NADPH oxidase and to initiate oxidative stress in the testis. The rhythmic contraction of seminiferous tubules propels sperm cells to the epididymis and depends on the stimulation of ET-1, which is secreted mainly by Sertoli's cells and Leydig's cells. Under intermittent hypoxia conditions, over-activation of $\mathrm{ET}_{\mathrm{A}} \mathrm{R}$ leads to an impairment in the movement of the tubules, impeding the final maturation of sperm cells in the epididymis.

Abnormal expression of MMP9 and Cx43 in isoproterenolinduced cardiovascular abnormality is related to $\mathrm{ET}_{\mathrm{A}} \mathrm{R}$ activation $^{[14]}$. Spermatogenesis is a highly programmed process that requires well-regulated degradation and remodeling of the extracellular matrix. The regulation of CD147 by MMP2 and MMP9 is essential for germ cell migration during spermatogenesis ${ }^{[36]}$. MMP9 is a key effector molecule in the increased neural stem cell proliferation and migration that occur during low $\mathrm{O}_{2}$ conditions. Decreased MMP9 expression adversely influences cell proliferation, cell migration and cell cycle kinetics in the testes. Gap junctional communication is achieved through a family of proteins named connexins, through which small molecules, such as ions and second messengers, and various other signaling molecules can be exchanged between cells $^{[37]}$. Cx43 is found in a variety of tissues, including the testes, and is responsible for conducting cell-to-cell communication via electrical and chemical coupling. Gap junctional communication via Cx43 plays an important role in normal testicular function because it normalizes the distribution of electrical heterogeneity ${ }^{[38]}$. The effectiveness of nifedipine and CPU86017-RS in relieving the hypoxia-induced abnormality of testicular Cx43 is likely the same as diltiazem ${ }^{[39]}$. Cx43 function is dependent on the connection of the two halves of the channels across the extracellular space; therefore, changes in the extracellular matrix may greatly impair this connection, resulting in a blockade of gap junctional communication and a dysfunctional testis.

Leptin, and its receptor OBRb, significantly modulates the function of reproductive cells in the testis. Leptin also affects the proliferation and differentiation of germ cells and modulates testicular steroidogenesis through autocrine/paracrine factors $^{[40]}$. Over-activation of testicular OBRb caused by intermittent hypoxia reflects a status of hyperleptinemia, which indicates the presence of oxidative stress related to over-activity of $\mathrm{ET}_{\mathrm{A}} \mathrm{R}$ and the sympathetic nerve system. As a result, over-expressed $\mathrm{OBRb}$ may damage testosterone biosynthesis by increasing $\mathrm{Ca}^{2+}$ influx in the testis. Therefore, treatment with nifedipine and CPU86017-RS is appropriate for the treatment of abnormal $\mathrm{OBRb}$ and $\mathrm{ET}_{\mathrm{A}} \mathrm{R}$, thereby ameliorating the dysfunction observed in hypoxic testes.

In conclusion, hypoxic testopathy is characterized by a downregulation of StAR, 3 $\beta$-HSD, and Cx43 expression and an upregulation of $\mathrm{ET}_{\mathrm{A}} \mathrm{R}, \mathrm{MMP} 9$ and $\mathrm{OBRb}$ expression. These changes are sensitive to both nifedipine and CPU86017-RS, which implies that the primary cause of the hypoxia-induced damage to the testicular cells is likely mediated by an increase in $\mathrm{Ca}^{2+}$ influx. CPU86017-RS and nifedipine attenuated the hypoxia-induced testicular dysfunction by normalizing the testicular expression of genes and pro-inflammatory biomarkers. Further investigation is needed to obtain direct evidence of the calcium-influx-blocking effect of CPU86017-RS and nifedipine in Leydig's cells.

\section{Acknowledgements}

This work was supported by the National Key New Drug Innovation Program, the Ministry of Science and Technology of China (Grant №: 2009ZXJ09004-070) and the National Natural Science Foundation of China (Grant No: 81070145).

\section{Author contribution}

Guo-lin ZHANG conducted the project, processed the data and prepared the manuscript. Feng YU assisted with the data processing. Yu-si CHENG and Can ZHANG provided the compounds. De-zai DAI and Yin DAI designed the project, discussed the underlying mechanisms and revised the manuscript.

\section{References}

1 Webb JD, Coleman ML, Pugh CW. Hypoxia, hypoxia-inducible factors (HIF), HIF hydroxylases and oxygen sensing. Cell Mol Life Sci 2009; 66: 3539-54.

2 Fahling M. Cellular oxygen sensing, signalling and how to survive translational arrest in hypoxia. Acta Physiol 2009; 195: 205-30. 
3 Sheldon RA, Osredkar D, Lee CL, Jiang X, Mu D, Ferriero DM. HIF1 alpha-deficient mice have increased brain injury after neonatal hypoxia-ischemia. Dev Neurosci 2009; 31: 452-8.

4 Takasawa M, Moustafa RR, Baron JC. Applications of nitroimidazole in vivo hypoxia imaging in ischemic stroke. Stroke 2008; 39: 1629-37.

5 Guo S, Miyake M, Liu KJ, Shi H. Specific inhibition of hypoxia inducible factor 1 exaggerates cell injury induced by in vitro ischemia through deteriorating cellular redox environment. J Neurochem 2009; 108 : 1309-21.

6 Li N, Dai DZ, Dai Y. CPU86017 and its isomers improve hypoxic pulmonary hypertension by attenuating increased $\mathrm{ET}_{\mathrm{A}}$ receptor expression and extracellular matrix accumulation. Naunyn Schmiedebergs Arch Pharmacol 2008; 378: 541-52.

7 Zhang TT, Cui B, Dai DZ, Tang XY. Pharmacological efficacy of CPU 86017 on hypoxic pulmonary hypertension in rats: mediated by direct inhibition of calcium channels and antioxidant action, but indirect effects on the ET-1 pathway. J Cardiovasc Pharmacol 2005; 46: 727-34.

8 Taniguchi H, Kawa G, Kinoshita H, Matsuda T, Asai A. Male hypogonadotropic hypogonadism $(\mathrm{MHH})$ outpatient with testosterone deficiency syndrome: a case report. Hinyokika kiyo 2009; 55: 107-9.

9 Feng Y, Zhang Q, Dai DZ, Ying HJ, Dai Y. Strontium fructose 1,6-diphosphate rescues adenine-induced male hypogonadism and upregulates the testicular endothelin-1 system. Clin Exp Pharmacol Physiol 2007; 34: 1131-7.

10 Xu M, Dai DZ, Zhang Q, Cheng YS, Dai Y. Upregulated NADPH oxidase contributes to diabetic testicular complication and is relieved by strontium fructose 1,6-diphosphate. Exp Clin Endocrinol Diabetes 2010; 118: 459-65.

11 Tang XY, Zhang Q, Dai DZ, Ying HJ, Wang QJ, Dai Y. Effects of strontium fructose 1,6-diphosphate on expression of apoptosis-related genes and oxidative stress in testes of diabetic rats. Int J Urol 2008; 15: $251-6$

12 Zhang Q, Liu HR, Ying HJ, Dai DZ, Tang XY, Dai Y. Strontium fructose 1,6-diphosphate alleviates early diabetic testopathy by suppressing abnormal testicular matrix metalloproteinase system in streptozocintreated rats. J Pharm Pharmacol 2009; 61: 229-36.

13 Hu C, Cong XD, Dai DZ, Zhang Y, Zhang GL, Dai Y. Argirein alleviates diabetic nephropathy through attenuating NADPH oxidase, $\mathrm{C} \times 43$, and PERK in renal tissue. Naunyn Schmiedebergs Arch Pharmacol 2011; 383: 309-19.

14 Peng HJ, Dai DZ, Ji H, Dai Y. The separate roles of endothelin receptors participate in remodeling of matrix metalloproteinase and connexin 43 of cardiac fibroblasts in maladaptive response to isoproterenol. Eur J Pharmacol 2010; 634: 101-6.

15 Steiner M, Weipoltshammer K, Viehberger G, Meixner EM, LungImayr G, Schöfer C. Immunohistochemical expression analysis of Cx43, Cx26, C-KIT and PIAP in contralateral testis biopsies of patients with nonseminomatous testicular germ cell tumor. Histochem Cell Biol 2011; 135: 73-81.

16 Zhang TT, Cui B, Dai DZ, Su W. CPU 86017, p-chlorobenzyltetrahyd roberberine chloride, attenuates monocrotaline-induced pulmonary hypertension by suppressing endothelin pathway. Acta Pharmacol Sin 2005; 26: 1309-16.

17 Dai DZ, Hu HJ, Zhao J, Hao XM, Yang DM, Zhou PA, et al. Blockade of L-type calcium channel in myocardium and calcium-induced contractions of vascular smooth muscle by CPU 86017 . Acta Pharmacol Sin 2004; 25: 416-23.

18 Dai DZ. CPU86017: a novel class III antiarrhythmic agent with multiple actions at ion channels. Cardiovasc Drug Rev 2006; 24: 101-15.

19 Du RH, Yi HW, Dai DZ, Tang WH, Dai Y. Inflammatory factors that contribute to upregulation of ERG and cardiac arrhythmias are sup- pressed by CPU86017, a class III antiarrhythmic agent. J Pharm Pharmacol 2008; 60: 1089-95.

20 Li N, Yang L, Dai DZ, Wang QJ, Dai Y. Chiral separation of racemate CPU86017, an anti-arrhythmic agent, produces stereoisomers possessing favourable ion channel blockade and less alpha-adrenoceptor antagonism. Clin Exp Pharmacol Physiol 2008; 35: 643-50.

21 Na T, Huang ZJ, Dai DZ, Zhang Y, Dai Y. Abrupt changes in FKBP12.6 and SERCA2a expression contribute to sudden occurrence of ventricular fibrillation on reperfusion and are prevented by CPU86017. Acta Pharmacol Sin 2007; 28: 773-82.

22 Bailey DM, Dehnert C, Luks AM, Menold E, Castell C, Schendler G, et al. High-altitude pulmonary hypertension is associated with a free radical-mediated reduction in pulmonary nitric oxide bioavailability. J Physiol 2010; 588: 4837-47.

23 Andreassen AK, Geiran O, Madsen S, Hognestad A, Simonsen S. Pulmonary arterial hypertension treated with prostacyclin or calcium blockers. Tidsskr Nor Laegeforen 2003; 123: 3393-6.

24 Rosati E, Butera G, Bossone E, De Felice C, Latini G. Inhaled nitric oxide and oral nifedipine in a preterm infant with bronchopulmonary dysplasia and pulmonary hypertension. Eur J Pediatr 2007; 166: 737-8.

25 Maggiorini M. High altitude-induced pulmonary oedema. Cardiovasc Res 2006; 72: 41-50.

26 Richardson A, Watt P, Maxwell N. Hydration and the physiological responses to acute normobaric hypoxia. Wild Environ Med 2009; 20: 212-20.

27 Hodkinson PD, Hunt BJ, Parmar K, Ernsting J. Is mild normobaric hypoxia a risk factor for venous thromboembolism? J Thromb Haemost 2003; 1: 2131-3.

28 Cheng YS, Dai DZ, Dai Y. Testis dysfunction by isoproterenol is mediated by upregulating endothelin receptor $\mathrm{A}$, leptin and protein kinase Cvarepsilon and is attenuated by an endothelin receptor antagonist CPU0213. Reprod Toxicol 2010; 29: 421-6.

29 Luo L, Chen H, Zirkin BR. Temporal relationships among testosterone production, steroidogenic acute regulatory protein (StAR), and P450 side-chain cleavage enzyme (P450scc) during Leydig cell aging. J Androl 2005; 26: 25-31.

30 Rangel PL, Rodriguez A, Rojas S, Sharp PJ, Gutierrez CG. Testosterone stimulates progesterone production and STAR, P450 cholesterol sidechain cleavage and LH receptor mRNAs expression in hen (Gallus domesticus) granulosa cells. Reproduction 2009; 138: 961-9.

31 Lawson C, Goupil S, Leclerc P. Increased activity of the human sperm tyrosine kinase SRC by the CAMP-dependent pathway in the presence of calcium. Biol Reprod 2008; 79: 657-66.

32 Boni R, Gualtieri R, Talevi R, Tosti E. Calcium and other ion dynamics during gamete maturation and fertilization. Theriogenology 2007; 68: S156-64.

33 Lee JH, Ahn HJ, Lee SJ, Gye MC, Min CK. Effects of L- and T-type $\mathrm{Ca}^{2+}$ channel blockers on spermatogenesis and steroidogenesis in the prepubertal mouse testis. J Assist Reprod Genet 2011; 28: 23-30.

34 Tang XY, Liu Q, Dai DZ, Dai Y. CPU0213, a novel endothelin receptor antagonist, suppresses the upregulation of matrix metalloproteinases and connexin 43 in hyperthyroid myocardium. Pharmacol Rep 2008; 60: 524-31.

35 Su W, Dai DZ, Liu HR, Na T, Dai Y. Upregulated endothelin system in diabetic vascular dysfunction and early retinopathy is reversed by CPU0213 and total triterpene acids from Fructus Corni. Clin Exp Pharmacol Physiol 2007; 34: 1228-33.

36 Chen H, Fok KL, Yu S, Jiang J, Chen Z, Gui Y, et al. CD147 is required for matrix metalloproteinases-2 production and germ cell migration during spermatogenesis. Mol Hum Reprod 2011; 17: 405-14. 
37 Izzo G, Ferrara D, Delrio G, d'Istria M, Minucci S. Connexin43 expression in the testis of frog Rana esculenta: sex hormonal regulation. Ann NY Acad Sci 2009; 1163: 425-7.

38 Guan K, Wagner S, Unsold B, Maier LS, Kaiser D, Hemmerlein B, et al. Generation of functional cardiomyocytes from adult mouse spermatogonial stem cells. Circ Res 2007; 100: 1615-25.

39 Matsushita S, Kurihara H, Watanabe M, Okada T, Sakai T, Amano A.
Inhibition of connexin43 dephosphorylation is involved in protective effects of diltiazem on cardiac function during hypoxic injury. Histol Histopathol 2011; 26: 315-22.

40 Herrid M, O'Shea T, McFarlane JR. Ontogeny of leptin and its receptor expression in mouse testis during the postnatal period. Mol Reprod Dev 2008; 75: 874-80. 